\title{
Physicians, CIHR call for more H1N1 research funds
}

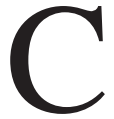

anadian physicians and researchers are calling on the federal and provincial governments to join other industrialized countries in fast-tracking funding for immediate applied research on the pandemic (H1N1) 2009 influenza virus to help combat an expected second wave of infection.

Researchers are already compiling data on the H1N1 patients in Canada and attempting to answer questions such as which people are suffering with the accompanying severe lung injuries; why and whether early treatment stops its progression; what kind of isolation techniques are most effective and for how long; and what management techniques work best. They also need to know how best to protect health care workers. In addition, the researchers are seeking answers about which patients who have a severe case of the disease are most likely to survive, and which are not, in case difficult triage decisions are necessary.

But the researchers say they're working with limited resources, largely on their own time.

"We need people to describe these patients, we need to do clinical trials now and resources need to be freed up for it," says Dr. Rob Fowler, a critical care physician in Toronto, Ontario and member of the Canadian Critical Care Trials Group who is helping to coordinate the effort. "This can't be something that we announce support for in November."

Fowler and Manitoba colleague Dr. Anand Kumar praised both the Public Health Agency of Canada and the Canadian Institutes of Health Research (CIHR) for making whatever funds they have available. "Everybody's doing the best they can and trying to lobby the powers that be to release the funds," says Kumar.

Both stressed the need for more fed-

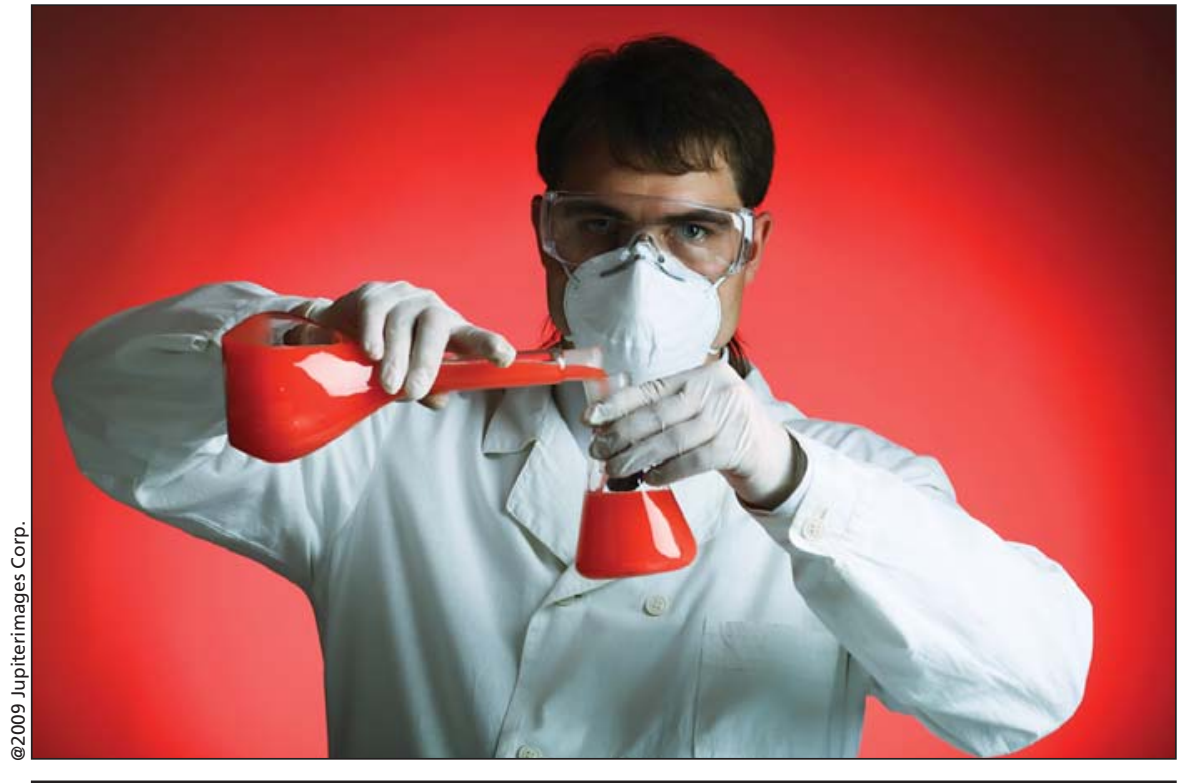

The Canadian Institutes of Health Research says it has reduced its application-tofunding timeline for swine flu research to 10 weeks.

eral dollars. "The resources that researchers and planners need at this point is trivial compared to the economic impact of this on all aspects of life," says Fowler.

On July 14, the Canadian Institutes of Health Research announced $\$ 1.2$ million in "catalyst" funding for H1N1 research. But even with an accelerated review process, those grants will not be awarded until October 30.

"It normally takes $12-18$ months to fund a request for proposals at CIHR," says Bhagirath Singh, the Institutes' scientific director. "In this case, the application, peer-review and start of funding have been reduced to 10 weeks and funding will be allocated right after."

By contrast, in June, Australia announced A\$7 million (Can\$6.2 million) for H1N1 research. The government used international experts to streamline the peer review process, making determinations on 41 medical projects in less than a week. Monies issued July 8.
Noting that " $\$ 1.2$ million is not a lot of money," Singh says CIHR is working to get provincial government and agencies, industry, health charities and the federal government to contribute more. "Ultimately the government of Canada has to step up to the plate, and obviously that's what we are working on. Our goal is to make sure that Canada is ready, and given the situation of H1N1, which wasn't predicted, it's not something we could have set money aside for. We have to look for new money."

Fowler adds that "we really want to make a plea to the folks that supply funds to federal agencies including the Public Health Agency of Canada, CIHR and the national medical lab, that this should not be downplayed. This is the time to move, because a couple of months from now, it's going to be way too late." — Laura Eggertson, Ottawa, Ont.

DOI:10.1503/cmaj.109-3014 